\title{
Perceived Autonomy Support from Peers, Parents, and Physical Education Teachers as Predictors of Physical Activity and Health-Related Quality of Life among Adolescents-A One-Year Longitudinal Study
}

\author{
Henri Tilga *(D), Hanna Kalajas-Tilga, Vello Hein, Lennart Raudsepp and Andre Koka (D) \\ Institute of Sport Sciences and Physiotherapy, Faculty of Medicine, University of Tartu, 51008 Tartu, Estonia; \\ hanna.kalajas-tilga@ut.ee (H.K.-T.); vello.hein@ut.ee (V.H.); lennart.raudsepp@ut.ee (L.R.); \\ andre.koka@ut.ee (A.K.) \\ * Correspondence: henri.tilga@ut.ee; Tel.: +372-53-818-440
}

Citation: Tilga, H.; Kalajas-Tilga, H.; Hein, V.; Raudsepp, L.; Koka, A. Perceived Autonomy Support from Peers, Parents, and Physical Education Teachers as Predictors of Physical Activity and Health-Related Quality of Life among

Adolescents-A One-Year Longitudinal Study. Educ. Sci. 2021, 11, 457. https://doi.org/10.3390/ educsci11090457

Academic Editor: Eila Jeronen

Received: 1 August 2021

Accepted: 20 August 2021

Published: 24 August 2021

Publisher's Note: MDPI stays neutral with regard to jurisdictional claims in published maps and institutional affiliations.

Copyright: (c) 2021 by the authors. Licensee MDPI, Basel, Switzerland. This article is an open access article distributed under the terms and conditions of the Creative Commons Attribution (CC BY) license (https:// creativecommons.org/licenses/by/ $4.0 /)$.

Abstract: The current research adopts the trans-contextual model of motivation (TCM) to examine the role of perceived autonomy support from peers, parents, and physical education (PE) teachers on adolescents' autonomous motivation, intentions, and physical activity (PA) and health-related quality of life (HRQoL) over a one-year period. Adolescents $(\mathrm{N}=264)$ aged between 11 and 15 years $(\mathrm{M}=13.24 ; \mathrm{SD}=0.96)$ filled in relevant questionnaires during a four-wave longitudinal study. Perceived autonomy support from peers, parents, and PE teachers predicted PA $(\beta \geq 0.03$, $p<0.009)$ and HRQoL $(\beta \geq 0.01, p<0.009)$ mediated by constructs of TCM over a one-year period. The regressions of PA $(\beta=0.45, p<0.001)$ and HRQoL $(\beta=0.56, p<0.001)$ on themselves over a one-year period were significant. PA significantly predicted the HRQoL measured one year later ( $\beta=0.20, p<0.001)$, but not vice versa $(\beta=0.04, p=0.52)$. The unidirectional cross-lagged relationship with the flow from PA to later HRQoL suggests that intervention programs focusing on promoting PA behaviour in adolescents should produce the most pronounced effects if their aim is also to promote HRQoL.

Keywords: physical activity; health-related quality of life; autonomy support; trans-contextual model of motivation; adolescents; physical education; motivation; self-determination theory

Physical activity (PA) and health-related quality of life (HRQoL, i.e., "a person's subjective evaluations of the influences of their current health status, health care, and health promoting activities on their ability to achieve and maintain a level of overall functioning that allows them to pursue valued life goals and that is reflected in their general wellbeing", [1]) have been endorsed as key outcomes in paediatric population health [2,3]. Previous research has demonstrated that adolescents' PA and HRQoL are in a period of sharp decline [4,5]. Importantly, research has highlighted that low levels of adolescent PA and HRQoL contribute to a higher risk of several diseases in adulthood [5,6]. Previous research has demonstrated that support from others, such as from parents, peers, and teachers, might have considerable influence on adolescents' health-related experiences $[7,8]$. Thus, it is important to identify the determinants of PA and HRQoL in order to inform significant social agents such as teachers, peers, and parents with practices that may enhance PA and HRQoL among adolescents.

A large amount of research has adopted the trans-contextual model of motivation (TCM; [9]) as a theoretical basis from which to emphasise the positive effect of perceived autonomy support from parents, peers, and physical education (PE) teachers on adolescents' adaptive outcomes. TCM is a well-known and highly recognised model of motivation that integrates concepts from self-determination theory (SDT; [10]), the theory of planned behaviour (TPB; [11]), and the hierarchical model of intrinsic and extrinsic motivation [12]. Central to the TCM is autonomous motivation, which reflects engaging in 
activities out of a sense of volition, interest, and choice or to attain self-endorsed goals. Based to the TCM, social agents such as teachers, peers, and parents have the potential to promote autonomous motivation by exhibiting autonomy-supportive behaviour toward others $[13,14]$. Specifically, several need-supporting techniques (e.g., providing choice; providing a meaningful rationale; using noncontrolling, informative language) have recently been proposed to show how significant others such as peers, parents, and teachers could enhance adolescents' autonomous motivation to engage in particular behaviour [8]. Additionally, a large amount of research in the educational context has demonstrated that students who perceive their teachers as providing autonomy support tend to report higher levels of autonomous motivation in an educational context [7]. Additionally, support from teachers has been identified as an important resource that increases adolescents' motivation to engage in PA [15].

Previous research based on the TCM has effectively demonstrated that autonomous motivation in the educational context will transfer to autonomous motivation in the leisure time (LT) context [9]. The reason for this is that adolescents' who perceive autonomous motivation in a specific context such as PE will seek out further opportunities to experience autonomous motivation in other contexts such as LT. In line with the core tenets of TCM, adolescents who experience autonomous motivation to engage in activities in both PE and LT contexts possibly form their beliefs and intentions to seek opportunities to engage in those activities in the future [16]. Based on the TCM, beliefs and intentions toward specific activities such as PA are the processes by which autonomous motivation turns toward achieving an actual behaviour or outcome, such as self-reported PA. Thus, beliefs and intentions are expected to be most proximal predictors of self-reported PA. Specifically, intention to engage in an activity is the mediating effect of the beliefs from TPB, such as attitudes, subjective norms, and perceived behavioural control relating to self-reported PA. Previous research has effectively demonstrated that these beliefs mediate the association between autonomous motivation and PA [17].

Previous longitudinal research in the framework of TCM has mainly used self-reported PA as an outcome $[18,19]$. Specifically, previous TCM studies have consistently reported a significant positive association between intention and self-reported PA over a longer period, such as three months [19] and 12 months [18]. Although effective in terms of data collection, self-reported measures of PA are subject to several biases, such as recall bias [20]. To gain more objective information about the intentions of the determinants towards more objective PA, several longitudinal studies measuring PA with accelerometers have been carried out [21,22]. However, these recent TCM-based studies that have adopted a longitudinal approach and used accelerometer-based PA as an outcome have failed to demonstrate a significant association between intention and accelerometer-based PA [21,22]. Thus, there is a need to carry out an additional investigation of TCM predicting PA to solve this disparity in the literature. In the current study, we use the framework of TCM and adopt a longitudinal approach to examine whether perceived autonomy support from PE teachers, parents, and peers predicts self-reported PA among adolescents via the components of the TCM. Additionally, we test whether effects on adolescents' PA will be evident throughout a one-year follow-up period.

Previous research has demonstrated that social agents can have a considerable impact on adolescents' HRQoL $[23,24]$. Specifically, behaviours exhibited by peers, parents, and teachers can have an influence on adolescents' HRQoL. For example, autonomy support from peers and teachers has been shown to be related to adolescents' HRQoL [25]. Additionally, previous research has effectively demonstrated that peer support is related to PA and mediated via enjoyment [26]. Based on SDT, perceived autonomy support from significant others provides a sense of ownership and responsibility toward behaviours, and is related to interest, enjoyment, and the persistence of the behaviour. Specifically, adolescents who perceive their peers, parents, and teachers as supportive of their autonomy might report a higher HRQoL. Thus, in the current study we expect autonomy support from peers, parents, and PE teachers to predict HRQoL via the components of TCM and 
PA. Additionally, previous research has consistently reported that higher levels of PA are associated with a better HRQoL [27]. Thus, understanding and experiencing the benefits of regular PA might be the key predictor of higher levels of HRQoL. In a recent study [28], it was found that self-reported PA was related to HRQoL, and it was suggested that future studies should investigate the direct effect of PA on HRQoL in a longitudinal approach. Specifically, a longitudinal test of the use of TCM for predicting HRQoL might provide more information about the causality of effects. Importantly, it might be the case that the PA of adolescents is the key mediator of effects between the constructs of TCM and adolescent HRQoL. Thus, we additionally test whether the effects on adolescents' HRQoL can be seen over a one-year follow-up period.

\section{The Present Study}

The current research adopts the TCM as a theoretical framework for investigating the effect of perceived autonomy support from peers, parents, and PE teachers on adolescents ${ }^{\prime}$ PA and HRQoL. An additional objective is to investigate the reciprocal relationships between adolescents' HRQoL and PA over a one-year period. The hypothesised model demonstrating the expected associations is presented in Figure 1. Based on the aim of this study, we propose the following hypotheses:

Hypothesis 1 (H1). Perceived autonomy support from PE teachers is expected to predict adolescents' autonomous motivation in $P E$, which, in turn, is expected to predict autonomous motivation in LT.

Hypothesis 2 (H2). Perceived autonomy support from peers and parents is expected to directly predict adolescents' autonomous motivation in LT.

Hypothesis 3 (H3). Autonomous motivation in LT is expected to predict adolescents' PA via self-reported attitudes, subjective norms, perceived behavioural control, and intentions.

Hypothesis 4 (H4). Perceived autonomy support from PE teachers, parents, and peers is expected to predict PA among adolescents via the components of the TCM.

Hypothesis 5 (H5). Perceived autonomy support from peers, parents, and PE teachers is expected to predict adolescents' HRQoL via the components of TCM and PA.

Hypothesis 6 (H6). Effects on adolescents' PA are expected to be evident over a one-year follow-up period.

Hypothesis 7 (H7). Effects on adolescents' HRQoL are expected to be evident over a one-year follow-up period.

Hypothesis 8 (H8). Adolescents' PA is expected to be able to predict adolescents' HRQoL over a one-year follow-up period.

Hypothesis 9 (H9). Adolescents' HRQoL is expected to be able to predict adolescents' PA over a one-year follow-up period. 


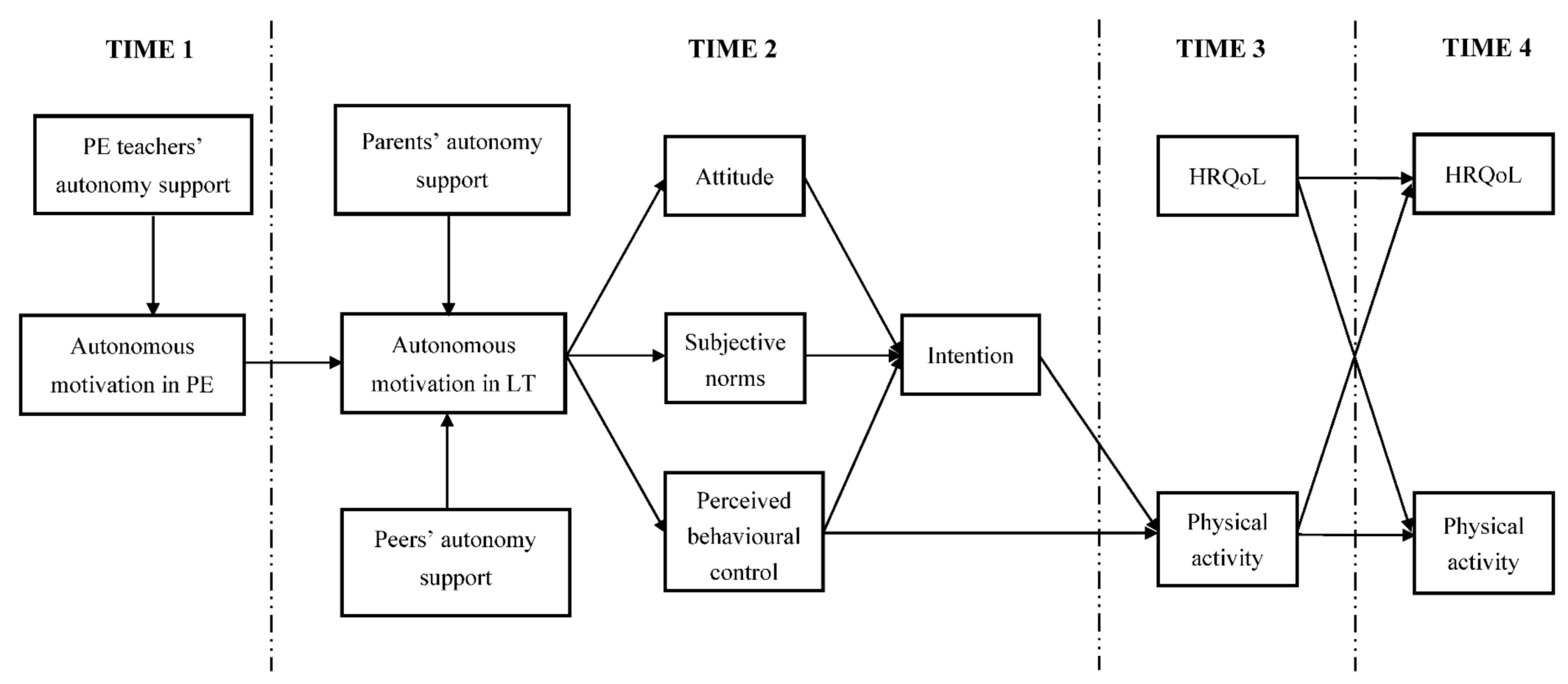

Note. $\mathrm{PE}=$ physical education, $\mathrm{LT}=$ leisure time, $\mathrm{HRQoL}=$ health-related quality of life. For clarity, error covariances among perceived autonomy support from PE teachers, parents and peers, among attitude, subjective norms and perceived behavioural control, and among HRQoL and physical activity at both time points are omitted.

Figure 1. The hypothesised model demonstrating the expected associations. 


\section{Method}

\section{Participants and Procedure}

The participants were 264 adolescents (195 boys and 69 girls) aged between 11 and 15 years old $(M=13.24 ; S D=0.96)$. All the participants were randomly selected from different schools in Estonia. A four-wave longitudinal design was used. Adolescents answered questions about perceived autonomy support from PE teachers, peers, and parents; autonomous motivation in PE at baseline (T1); autonomous motivation in leisure time; constructs of theory of planned behaviour five weeks later (T2); self-reported PA and HRQoL another five weeks later (T3); and self-reported PA and HRQoL at one-year followup (T4). Informed consent for participation in this study was collected from the adolescents and their parents. Adolescents were informed that their responses should reflect their own opinions and that there were no correct or incorrect answers. Questionnaires were filled in anonymously and matched (from T1 to T4) using an individual code with numbers and letters based on the participants' initials, birth date, gender, and class. The Ethical Committee of Tartu University approved the study protocol.

\section{Measures}

Constructs of perceived autonomy support from peers, parents, and PE teachers; autonomous motivation in PE and LT; and constructs of TCM were measured on validated psychometric instruments, with responses provided on 7-point scales (from " 1 = strongly disagree" to "7 = strongly agree").

\subsection{Perceived Autonomy Support from Peers, Parents and PE Teachers}

Adolescents' perceptions of autonomy-supportive behaviour from peers, parents, and PE teachers were measured by the short form of the Perceived Autonomy Support Scale for Exercise Settings (PASSES; [29]). There were four items for each subscale (e.g., "I feel that my friends/parents/PE teacher provides me with choices, options, and suggestions about whether to do physical activity"). Previous studies have demonstrated that PASSES is a reliable and valid instrument $[21,22]$.

\subsection{Autonomous Motivation towards PE}

Adolescents' autonomous forms of motivation toward PE were measured by the adapted version of the perceived locus of causality questionnaire (PLOC-PE; [30]). Each subscale comprised two items and was presented with a common stem: "I do PE ..." followed by the set of items: intrinsic motivation (e.g., " ... because I enjoy PE") and identified regulation (e.g., " ... because it is important to me to improve in PE"). The autonomous motivation in the PE construct was formed based on the average scores for the intrinsic motivation and identified regulation subscales. Previous studies have demonstrated that PLOC is a reliable and valid instrument [22,31,32].

\subsection{Autonomous Motivation towards during Leisure Time}

Adolescents' autonomous forms of motivation during leisure time were measured using an adapted version of the perceived locus of causality questionnaire (PLOC-LT; [33]). Each subscale comprised two items and was presented with a common stem, "I do physical activity during my free time ... " followed by the set of items: intrinsic motivation (e.g.," ... because it is fun") and identified regulation (e.g., ". . . because it's important to me to do physical activities"). The autonomous motivation during leisure time construct was formed based on the average scores for the intrinsic motivation and identified regulation subscales. Previous studies have demonstrated that PLOC is a reliable and valid instrument [21,22,32].

\subsection{Attitude, Subjective Norms, Perceived Behavioural Control, and Intentions}

TPB constructs [34] such as attitude, subjective norms, perceived behavioural control, and intentions were measured by a previously developed and validated scale $[21,22,35]$. Two items were used to measure intentions (e.g., "I plan to do active sports and/or vigor- 
ous physical activities during my leisure time in the next 5 weeks"). To measure attitudes, the following common stem was presented, "Participating in active sports and/or vigorous physical activities during my leisure time in the next 5 weeks is ..." to which responses were provided on three 7-point semantic differential scales with bipolar adjectives: "bad-good", "unenjoyable-enjoyable", and "useless-useful". Two items were used to measure subjective norms (e.g., "Most people important to me put pressure on me to do active sports and/or vigorous physical activities during my leisure time for the next 5 weeks"). Perceived behavioural control was also measured by two items (e.g., "I am confident I could do active sports and/or vigorous physical activities during my leisure time in the next 5 weeks"). Previous studies have demonstrated that this measure is reliable and valid [36].

\subsection{Self-Reported Physical Activity}

An adapted version of Godin and Shepherd's [37] leisure time exercise questionnaire (LTEQ) was used to measure adolescents' self-reported leisure time physical activity. In total, there were two items: "In the course of the past five weeks, how often on average, have you participated in vigorous physical activities during your leisure time for at least $20 \mathrm{~min}$ at a time?", with responses provided on a 6-point scale (from " $1=$ never" to " 6 = all of the time"), and "In the course of the past five weeks, how often on average, have you participated in vigorous physical activities during your leisure time for at least 20 min at a time?", with responses reported on a 6-point scale (from " $1=$ not at all" and " $6=$ most days per week"). Previous studies have demonstrated that this measure is reliable and valid $[21,22,38-40]$.

\section{6. $H R Q o L$}

Adolescents' HRQoL was measured by an adapted and validated version [41] of the 23-item paediatric quality of life inventory 4.0 generic core scale (PedsQL ${ }^{\mathrm{TM}} 4.0$; [42]). The scale consists of five dimensions: physical health (eight items, e.g., "It is hard for me to run"), emotional functioning (five items, e.g., "I feel afraid or scared"), social functioning (five items, e.g., "Other kids tease me"), school-related functioning (three items, e.g., "It is hard to pay attention in class"), and days missed from school due to illness (two items, e.g., "I miss school to go to the doctor or hospital"). Adolescents were told to report how much of a problem this had been during the past one month. Participants provided responses on a five-point scale (from " $0=$ strongly disagree" to " $4=$ strongly agree"). Items were reverse-scored and linearly transformed to a 0 to 100 scale prior to data analysis (i.e., $0=100,1=75,2=50,3=25$, and $4=0$ ). Previous studies have demonstrated that this measure is reliable and valid $[24,25,43]$.

\section{Data Analysis}

Data analysis was conducted using SPSS Version 23.0 (IBM Corp., Armonk, NY, USA) and SPSS AMOS Version 23.0 (IBM Corp., Armonk, NY, USA). Based on the suggestions made by Hu and Bentler [44], multiple goodness-of-fit indices were used to examine the fit of the proposed model with the data. An acceptable fit of the data with the hypothesised model is shown by values $\geq 0.90$ for the comparative fit index (CFI) and the BentlerBonett non-normed fit index (NNFI) and a value $\leq 0.08$ for the root mean square error of approximation (RMSEA) [44].

Firstly, composite scores for the PE teachers', parents', and peers' autonomy support; autonomous motivation in LT and PE; attitude; subjective norms; perceived behavioural control; intention; PA and HRQoL were calculated as the average of the item scores for each scale. Secondly, a path analytic model with the direct paths specified in Figure 1 was created. In addition, the path model included correlations between perceived autonomy support from peers, parents, and PE teachers; between attitude, subjective norms, and perceived behavioural control; and between PA and HRQoL. Thirdly, the adequacy of the 
data fit for the path model with 13 indicators was estimated. Fourthly, based on the results of the path analysis, we tested the study hypotheses.

\section{Results}

\subsection{Preliminary Analysis}

The examination of skewness (range $=-2.033$ to 1.724 ) and kurtosis (range $=-1.109$ to 5.275) values indicated that all the items were within acceptable ranges [45]. Descriptive statistics, zero-order intercorrelations, and internal consistency values for all the study variables are presented in Table 1.

Table 1. Zero-order intercorrelations, descriptive statistics, and reliability scores for study variables among the study sample.

\begin{tabular}{|c|c|c|c|c|c|c|c|c|c|c|c|c|c|}
\hline \multirow{2}{*}{ Variables } & \multicolumn{12}{|c|}{ Correlations } & \multirow[b]{2}{*}{13} \\
\hline & 1 & 2 & 3 & 4 & 5 & 6 & 7 & 8 & 9 & 10 & 11 & 12 & \\
\hline & & & & & & & & & & & & & \\
\hline $\begin{array}{l}\text { 2. Parents' autonomy support (T2) } \\
\text { 3. PE teachers' autonomy support (T1) }\end{array}$ & $\begin{array}{l}0.30 * * \\
0.40 *\end{array}$ & $0.24 * *$ & & & & & & & & & & & \\
\hline 4. Autonomous motivation in PE (T1) & 0.25 *** & $0.20^{* *}$ & $0.45^{* * *}$ & & & & & & & & & & \\
\hline 5. Autonomous motivation in LT (T2) & $0.38^{* *}$ & 0.35 ** & $0.26 * *$ & $0.51^{* *}$ & & & & & & & & & \\
\hline 6. Attitude (T2) & $0.26^{* *}$ & $0.27^{* *}$ & $0.14^{*}$ & $0.36 * * *$ & $0.60 * * *$ & & & & & & & & \\
\hline 7. Subjective norms (T2) & $0.19^{* *}$ & 0.07 & 0.10 & 0.08 & 0.20 ** & $0.18^{*}$ & & & & & & & \\
\hline 8. Perceived behavioural control (T2) & $0.26^{* * *}$ & $0.31 * *$ & $0.23 * *$ & $0.33 * * *$ & $0.57 * * *$ & $0.60^{* * *}$ & $0.25^{* * *}$ & & & & & & \\
\hline 9. Intention (T2) & $0.36^{* * *}$ & $0.31 * *$ & $0.19^{* *}$ & $0.30^{* * *}$ & $0.63^{* * *}$ & $0.66^{* * *}$ & $0.30^{* * *}$ & $0.66^{* * *}$ & & & & & \\
\hline 10. Physical activity (T3) & $0.28^{* * *}$ & 0.17 & 0.11 & $0.14 *$ & $0.39 * * *$ & $0.37 * * *$ & $0.24 * * *$ & $0.49^{* * *}$ & $0.56^{* * *}$ & & & & \\
\hline 11. HRQoL (T3) & $0.18^{*}$ & $0.21 * *$ & $0.23^{* * *}$ & $0.21 * *$ & $0.25 * * *$ & $0.23^{* * *}$ & 0.04 & $0.26^{* * *}$ & $0.23^{* * *}$ & $0.21 * *$ & & & \\
\hline 12. Physical activity (T4) & 0.19 ** & $0.11^{*}$ & 0.07 & $0.15^{*}$ & $0.27^{* * *}$ & $0.26^{* * *}$ & 0.11 & $0.22 * * *$ & $0.36^{* * *}$ & $0.46^{* * *}$ & $0.13^{*}$ & & \\
\hline 13. HRQoL (T4) & $0.17^{*}$ & $0.22 * *$ & 0.12 & $0.15^{* *}$ & $0.28^{* * *}$ & $0.27 * * *$ & $0.12^{*}$ & $0.29 * * *$ & $0.33^{* * *}$ & $0.32 * * *$ & $0.59 * * *$ & $0.27^{* * *}$ & \\
\hline $\mathrm{M}$ & 4.95 & 5.98 & 5.25 & 5.67 & 5.86 & 6.09 & 4.23 & 5.59 & 5.70 & 4.35 & 1.05 & 4.38 & 1.23 \\
\hline SD & 1.41 & 1.08 & 1.20 & 1.24 & 1.14 & 1.02 & 1.47 & 1.18 & 1.28 & 1.10 & 0.55 & 1.05 & 0.61 \\
\hline$\alpha$ & 0.90 & 0.86 & 0.84 & 0.80 & 0.88 & 0.84 & 0.67 & 0.81 & 0.93 & 0.88 & 0.91 & 0.90 & 0.93 \\
\hline
\end{tabular}

Note. $\mathrm{PE}=$ physical education, $\mathrm{LT}=$ leisure time, $\mathrm{HRQoL}=$ health-related quality of life, $\mathrm{T} 1=\mathrm{Time} 1, \mathrm{~T} 2=\mathrm{Time} 2, \mathrm{~T} 3=\mathrm{Time} 3$, $\mathrm{T} 4=\mathrm{Time} 4$. ${ }^{*} p<0.05,{ }^{* *} p<0.01,{ }^{* * *} p<0.001$.

\subsection{Main Analysis}

The path model with 13 indicators yielded a good fit with the data $\left(\chi^{2}=112.79\right.$, $\left.\mathrm{df}=54, \mathrm{CFI}=0.95, \mathrm{NNFI}=0.92, \mathrm{RMSEA}=0.064, \mathrm{CI}_{90} \mathrm{RMSEA}=0.048-0.081\right)$. Direct relationships among the study constructs are displayed in Figure 2. Perceived autonomy support from PE teachers predicted adolescents' autonomous motivation in PE ( $\beta=0.45, p<0.001)$, which, in turn, predicted their autonomous motivation in LT ( $\beta=0.42, p<0.001)$. Adolescents' autonomous motivation in LT is predicted by perceived autonomy support from peers $(\beta=0.22, p<0.001)$ and by perceived autonomy support from parents $(\beta=0.20, p<0.001)$. Autonomous motivation in LT predicted adolescents' PA at T3 $(\beta=0.31, p<0.001)$ and their PA at T4 $(\beta=0.14, p<0.001)$ via self-reported attitudes, subjective norms, perceived behavioural control, and intentions. Adolescents' PA at T3 is predicted by perceived autonomy support from PE teachers $(\beta=0.06, p<0.001)$, parents $(\beta=0.06, p<0.001)$, and peers $(\beta=0.07, p=0.009)$ via the components of the TCM. Adolescents' PA at T4 is predicted by perceived autonomy support from PE teachers $(\beta=0.03, p<0.001)$, parents $(\beta=0.03, p<0.001)$, and peers $(\beta=0.03, p=0.009)$ via the components of the TCM. Adolescents' HRQoL at T4 is predicted by perceived autonomy support from PE teachers $(\beta=0.01, p<0.001)$, parents $(\beta=0.01, p<0.001)$, and peers $(\beta=0.01, p=0.009)$ via the components of the TCM and PA. The regressions of PA $(\beta=0.45, p<0.001)$ and HRQoL $(\beta=0.56, p<0.001)$ on themselves over a one-year period (from T3 to T4) were significant. PA measured at T3 significantly predicted the HRQoL measured one year later at $\mathrm{T} 4(\beta=0.20, p<0.001)$, but not vice versa ( $\beta=0.04, p=0.52)$. The path model accounted for $37 \%$ of the variance in HRQoL at T4 and $20 \%$ of the variance in PA at T4. 


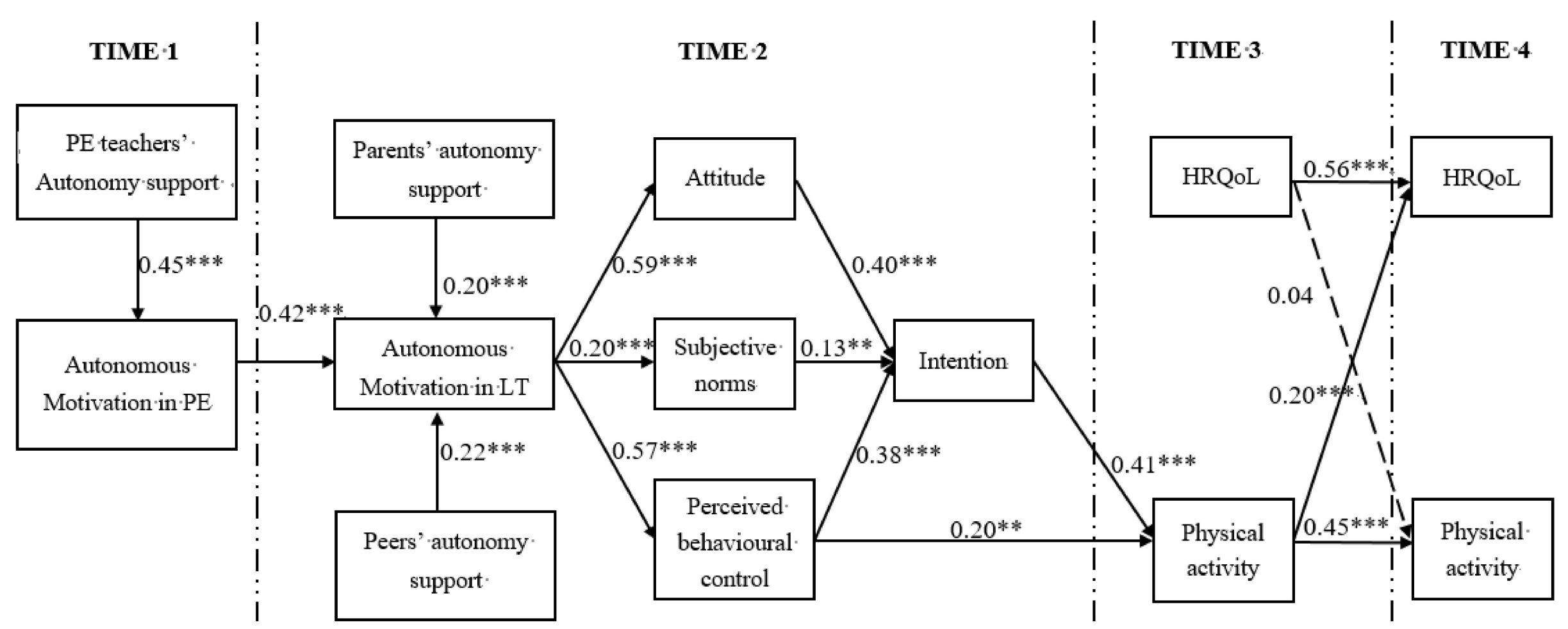

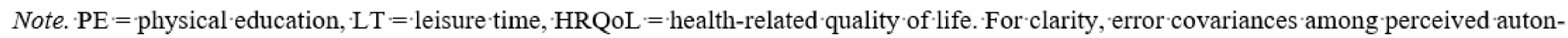
omy support from 'PE teachers, parents 'and peers, 'among attitude, 'subjective norms 'and perceived behavioural 'control, 'and 'among 'HRQoL 'and ' physical activity at 'both time ' points are 'omitted. Covariances ' of ' the error 'terms 'were 'as follows: ' $r$ ' peers' autonomy 'support - $\mathrm{PE}$ teachers' autonomy support ' $=$ '

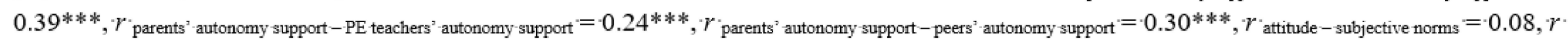

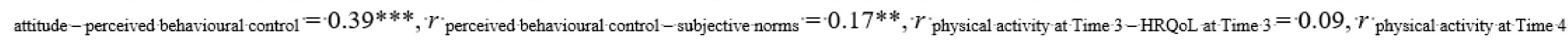
-HRQD at Time $4=0.15 * . * p<0.05, * * p<0.01, * * * p<0.001$.

Figure 2. The path model measuring the relationships between adolescents' perceived autonomy support received from physical education teachers, peers, and parents and adolescents' daily objectively measured physical activity and health-related quality of life via the components of the trans-contextual model of motivation. 


\section{Discussion}

The purpose of the current study was to investigate the effect of perceived autonomy support from peers, parents, and PE teachers on adolescents' PA and HRQoL with the additional objective of investigating the reciprocal relationships between adolescents' HRQoL and PA over a one-year period. Overall, all the main premises of the TCM were supported by the results of the current study.

Firstly, it was hypothesised that the factor of perceived autonomy support from PE teachers would be able to predict adolescents' autonomous motivation in PE, which, in turn, was expected to predict autonomous motivation in LT. In line with previous studies $[9,21,46]$, the current study also supports the notion of the autonomy support received from PE teachers being an important factor in enhancing adolescents' autonomous motivation during PE. In other words, if PE teachers try to understand how students' see things before suggesting doing things in a new way and encourage them, students' will be more likely to engage in PE because they will experience it as fun and enjoyable. Secondly, it was hypothesised that perceived autonomy support from peers and parents would be able to predict adolescents' autonomous motivation in LT. In line with previous studies $[9,13,21,46]$, the current study also supports the notion of autonomy support from peers and parents being an important additional source enhancing adolescents' autonomous motivation during LT. In other words, when students' engage in PE because they find it fun and enjoyable, it is likely that they will enjoy being physically active during their LT as well. In line with Hagger et al. [14], sources other than autonomy support from teachers are also important factors in adolescents' decision-making processes.

Thirdly, it was hypothesised that autonomous motivation in LT would predict adolescents' PA via self-reported attitudes, subjective norms, perceived behavioural control, and intentions. The current study confirmed the importance of autonomous motivation during LT to enhance adolescence' PA during LT. Importantly, this process is mediated by the constructs of attitudes, subjective norms, perceived behavioural control, and intentions. In other words, if adolescents experience fun during LT PA, they will tend to be physically active during their LT. This process is true when adolescents' also feel that people who are important to them think that they should be physically active; when they experience confidence during PA; when they find LT PA useful, good, and enjoyable; and when they actually intend to do PA during their LT. Fourthly, it was hypothesised that perceived autonomy support from PE teachers, parents, and peers would predict PA among adolescents via components of the TCM. The results of the current study demonstrate that adolescents' PA is facilitated by autonomy support from peers, parents, and PE teachers via the components of the TCM. In other words, if peers, parents, and PE teachers encourage adolescents to engage in physical activity, then adolescents will possibly be more physically active during their LT. Importantly, this process is mediated by adolescents' autonomous motivation during PE and LT, and self-reported components of the theory of planned behaviour. These finding are in accordance with the general tenets of the TCM [9]. This finding is also in line with previous studies, in which it was found that teachers' and classmates' support are important factors in predicting adolescents' PA [47].

Fifthly, it was hypothesised that perceived autonomy support from peers, parents, and PE teachers would predict adolescents' HRQoL via the components of TCM and PA. It was found that autonomy support from all social agents significantly predicted adolescents' HRQoL via the components of TCM and PA. In other words, if peers, parents, and PE teachers provide adolescents with choices and options, then adolescents' are most likely to feel, for example, that they have more energy, that they get along better with other children, and that they are less likely to forget things. This process is mediated by adolescents autonomous motivation towards PA, the components of theory of planned behaviour, and self-reported LT PA. This finding is similar to that of previous research in this field [25].

Sixth, it was hypothesised that PA would track to a one-year follow-up period. In line with previous similar research [48], adolescents' PA is related to their own PA one year later. In other words, adolescents who are physically active tend to be physically 
active in the long term. This finding is important because it demonstrates that autonomy support from social agents is likely a crucial component of long-term PA. Seventh, it was hypothesised that adolescents' HRQoL would track to a one-year follow-up period. In line with previous similar research [25], adolescents' HRQoL tracked to different time points. In other words, adolescents who report a better HRQoL tend to also report a higher HRQoL in the long term. This finding is important because it demonstrates that autonomy support from social agents is likely a crucial component of adolescents' long-term HRQoL. Eight, it was hypothesised that adolescents' PA would predict adolescents' HRQoL over a one-year follow-up period. In line with previous similar research [27], it was found that adolescents' PA predicted their HRQoL over a one-year period. This finding is important because it demonstrates the positive effect of adolescents' PA on their HRQoL. In other words, adolescents who tend to be physically active are likely to report a better HRQoL in the long term. Thus, interventions aiming to increase adolescents' HRQoL should likely also include measures promoting adolescents' PA. Ninth, it was hypothesised that adolescents' HRQoL would predict adolescents PA over a one-year follow-up period. The results of the current study did not support this hypothesis, as adolescents' HRQoL did not predict their PA over a one-year period. In other words, adolescents who already experience higher levels of HRQoL do not necessarily report higher levels of PA. This is possibly because HRQoL is a much wider concept that PA itself and, thus, there are other factors that might influence having higher levels of HRQoL. However, it was found that PA itself is a significant predictor of HRQoL. Based on this, one might argue that higher levels of PA might enhance adolescents' HRQoL, but if adolescents already experience higher levels of HRQoL, then this might not always be the result of a physically active lifestyle, as HRQoL is affected by more factors than PA alone.

\section{Strengths, Limitations and Future Research}

The present research has several strengths, including adopting a longitudinal design measuring study constructs at four time points; assessing autonomy support from several social agents, such as peers, parents, and PE teachers; using the TCM as a promising model to explain adolescents' PA and HRQoL; and having a solid sample size for a longitudinal study. The current findings extend previous research by demonstrating that autonomy support from all social agents, such as peers, parents, and PE teachers, is important in enhancing adolescents' PA and HRQoL. This is important information for practitioners and researchers designing future interventions with the aim of increasing adolescents' PA and HRQoL. Specifically, previous research has highlighted that, when PE teachers become more supportive of autonomy in their students, both students [7,49-52] and the teachers themselves [53,54] will gain various benefits. Based on this, future research should also test the intervention effects if parents and peers become more supportive of adolescents' autonomy.

Additionally, there are several limitations of this study. Firstly, we relied purely on self-reported data. Future research could use accelerometer-based devices to measure adolescents' PA and objective observations to capture autonomy-supportive behaviour from PE teachers. Secondly, our sample was mostly composed of female participants, which means that our results are better for describing female behaviours. Future studies should aim to find opportunities to include more male participants in their sample. Thirdly, we only measured the bright side of humans' behaviour, which is perceived autonomy support from peers, parents, and PE teachers, as well as autonomous forms of motivation (i.e., intrinsic motivation and identified regulation). Future research could investigate the effect of behaviours perceived as controlling from peers, parents, and PE teachers [55] on adolescents' experiences, perceptions of controlled forms of motivation (i.e., introjected and external regulation), and amotivation. This is important because previous research has highlighted the fact that adolescents are sensitive to controlling behaviours from PE teachers [56]. Fourthly, while the current design was a longitudinal study, the data are still correlational, which means that we cannot draw causal conclusions. Future research 
should adopt an experimental or intervention design to examine causal effects among study constructs. Finally, in the current study we measured adolescents' perceptions of autonomy-supportive behaviour using a unidimensional scale. Recent studies have demonstrated that the Multidimensional Perceived Autonomy Support Scale for Physical Education (MD-PASS-PE; [57]) has the potential to explain more variance in PE-related outcomes compared to unidimensional scales [55,58-61]. Future studies could benefit from adopting a multidimensional approach for measuring autonomy support from different social agents.

\section{Conclusions}

The current study fills a knowledge gap by using a longitudinal design for testing the effect of peers', parents', and PE teachers' autonomy support on adolescents' PA and HRQoL via the components of the TCM. The findings of the current study support the key tenets of the TCM. Additionally, the current study demonstrates that peers, parents, and PE teachers play an important role in enhancing adolescents' PA and HRQoL. Importantly, this process is mediated via autonomous motivation during PE and LT, attitudes, subjective norms, perceived behavioural control, and intentions. Additionally, the unidirectional cross-lagged relationship shown in the flow from PA to HRQoL one year later suggests that intervention programs focusing on promoting PA behaviour in adolescents would achieve more pronounced effects if their aim is also to promote HRQoL.

Author Contributions: Conceptualization, H.T., H.K.-T., V.H., L.R. and A.K.; Formal analysis, H.T.; Investigation, H.K.-T., H.T. and A.K.; Methodology, H.T.; Supervision, A.K.; Writing—original draft, H.T.; Writing-review \& editing, H.K.-T., V.H., L.R. and A.K. All authors have read and agreed to the published version of the manuscript.

Funding: This research received no external funding.

Institutional Review Board Statement: The study was conducted according to the guidelines of the Declaration of Helsinki, and approved by the Institutional Review Board of University of Tartu (protocol code 273/T-5 and date of approval 18 September 2017).

Informed Consent Statement: Informed consent was obtained from all subjects involved in the study. Data Availability Statement: Data supporting reported results can be found at https://osf.io/h4mtx/.

Conflicts of Interest: The authors declare no conflict of interest.

\section{References}

1. Shumaker, S.A.; Naughton, M.J. The international assessment of health-related quality of life: A theoretical perspective. In The International Assessment of Health-Related Quality of Life: Theory, Translation, Measurement and Analysis; Shumaker, S.A., Berzon, R.A., Eds.; Rapid Communication: Oxford, UK, 1995; pp. 3-10.

2. Meade, T.; Dowswell, E. Adolescents' health-related quality of life (HRQoL) changes over time: A three year longitudinal study. Health Qual. Life Outcomes 2016, 14, 14. [CrossRef] [PubMed]

3. Poitras, V.J.; Gray, C.E.; Borghese, M.M.; Carson, V.; Chaput, J.-P.; Janssen, I.; Katzmarzyk, P.T.; Pate, R.R.; Connor Gorber, S.; Kho, M.E.; et al. Systematic review of the relationships between objectively measured physical activity and health indicators in school-aged children and youth. Appl. Physiol. Nutr. Metab. Physiol. Appl. Nutr. Metab. 2016, 41 (Suppl. 3), S197-S239. [CrossRef] [PubMed]

4. Bisegger, C.; Cloetta, B.; von Rueden, U.; Abel, T.; Ravens-Sieberer, U.; European Kidscreen Group. Health-related quality of life: Gender differences in childhood and adolescence. Soz. Prav. 2005, 50, 281-291. [CrossRef]

5. Guthold, R.; Stevens, G.A.; Riley, L.M.; Bull, F.C. Global trends in insufficient physical activity among adolescents: A pooled analysis of 298 population-based surveys with 1.6 million participants. Lancet Child Adolesc. Health 2020, 4, 23-35. [CrossRef]

6. Mavrovouniotis, F. Inactivity in Childhood and Adolescence: A Modern Lifestyle Associated with Adverse Health Consequences. Sport Sci. Rev. 2012, 21, 75. [CrossRef]

7. Reeve, J.; Cheon, S.H. Autonomy-supportive teaching: Its malleability, benefits, and potential to improve educational practice. Educ. Psychol. 2021, 56, 54-77. [CrossRef]

8. Teixeira, P.J.; Marques, M.M.; Silva, M.N.; Brunet, J.; Duda, J.; Haerens, L.; La Guardia, J.; Lindwall, M.; Londsdale, C.; Markland, D.; et al. Classification of techniques used in self-determination theorybased interventions in health contexts: An expert consensus study. Motiv. Sci. 2020. [CrossRef] 
9. Hagger, M.S.; Chatzisarantis, N.L.D. The Trans-Contextual Model of Autonomous Motivation in Education: Conceptual and Empirical Issues and Meta-Analysis. Rev. Educ. Res. 2016, 86, 360-407. [CrossRef]

10. Deci, E.L.; Ryan, R.M. Intrinsic Motivation and Self-Determination in Human Behavior; Plenum Press: New York, NY, USA, 1985.

11. Ajzen, I. The theory of planned behavior. Organ. Behav. Hum. Decis. Process. 1991, 50, 179-211. [CrossRef]

12. Vallerand, R.J.; Ratelle, C.F. Intrinsic and extrinsic motivation: A hierarchical model. In Handbook of Self-Determination Research; Deci, E.L., Ryan, R.M., Eds.; University of Rochester Press: Rochester, NY, USA, 2002; pp. 37-63.

13. González-Cutre, D.; Sicilia, Á.; Beas-Jiménez, M.; Hagger, M.S. Broadening the trans-contextual model of motivation: A study with Spanish adolescents. Scand. J. Med. Sci. Sports 2014, 24, e306-e319. [CrossRef]

14. Hagger, M.S.; Chatzisarantis, N.L.D.; Hein, V.; Soos, I.; Karsai, I.; Lintunen, T.; Leemans, S. Teacher, peer and parent autonomy support in physical education and leisure time physical activity: A trans-contextual model of motivation in four nations. Psychol. Health 2009, 24, 689-711. [CrossRef]

15. Bronikowski, M.; Bronikowska, M.; Maciaszek, J.; Glapa, A. Maybe it is not a goal that matters: A report from a physical activity intervention in youth. J. Sports Med. Phys. Fit. 2018, 58, 348-355. [CrossRef]

16. Hagger, M.S.; Hardcastle, S.J.; Chater, A.; Mallett, C.; Pal, S.; Chatzisarantis, N. Autonomous and controlled motivational regulations for multiple health-related behaviors: Between-and within-participants analyses. Health Psychol. Behav. Med. 2014, 2, 565-601. [CrossRef] [PubMed]

17. Chan, D.K.C.; Zhang, L.; Lee, A.S.Y.; Hagger, M.S. Reciprocal relations between autonomous motivation from self-determination theory and social cognition constructs from the theory of planned behavior: A cross-lagged panel design in sport injury prevention. Psychol. Sport Exerc. 2020, 48, 101660. [CrossRef]

18. Raudsepp, L.; Viira, R.; Hannus, A. Prediction of Physical Activity Intention and Behavior in a Longitudinal Sample of Adolescent Girls. Percept. Mot. Skills 2010, 110, 3-18. [CrossRef]

19. Rhodes, R.E.; Macdonald, H.M.; McKay, H.A. Predicting physical activity intention and behaviour among children in a longitudinal sample. Soc. Sci. Med. 2006, 62, 3146-3156. [CrossRef]

20. Adams, S.A.; Matthews, C.E.; Ebbeling, C.B.; Moore, C.G.; Cunningham, J.E.; Fulton, J.; Hebert, J.R. The effect of social desirability and social approval on self-reports of physical activity. Am. J. Epidemiol. 2005, 161, 389-398. [CrossRef]

21. Kalajas-Tilga, H.; Hein, V.; Koka, A.; Tilga, H.; Raudsepp, L.; Hagger, M.S. Application of the trans-contextual model to predict change in leisure time physical activity. Psychol. Health 2021, 1-25. [CrossRef]

22. Polet, J.; Lintunen, T.; Schneider, J.; Hagger, M.S. Predicting change in middle school students' leisure-time physical activity participation: A prospective test of the trans-contextual model. J. Appl. Soc. Psychol. 2020, 50, 512-523. [CrossRef]

23. Standage, M.; Gillison, F. Students' motivational responses toward school physical education and their relationship to general self-esteem and health-related quality of life. Psychol. Sport Exerc. 2007, 8, 704-721. [CrossRef]

24. Standage, M.; Gillison, F.B.; Ntoumanis, N.; Treasure, D.C. Predicting students' physical activity and health-related well-being: A prospective cross-domain investigation of motivation across school physical education and exercise settings. J. Sport Exerc. Psychol. 2012, 34, 37-60. [CrossRef]

25. Koka, A. The relative roles of teachers and peers on students' motivation in physical education and its relationship to self-esteem and Health-Related Quality of Life. Int. J. Sport Psychol. 2014, 45, 187-213. [CrossRef]

26. Chen, H.; Sun, H.; Dai, J. Peer Support and Adolescents' Physical Activity: The Mediating Roles of Self-Efficacy and Enjoyment. J. Pediatr. Psychol. 2017, 42, 569-577. [CrossRef]

27. Anokye, N.K.; Trueman, P.; Green, C.; Pavey, T.G.; Taylor, R.S. Physical activity and health related quality of life. BMC Public Health 2012, 12, 624. [CrossRef]

28. Wunsch, K.; Nigg, C.R.; Weyland, S.; Jekauc, D.; Niessner, C.; Burchartz, A.; Schmidt, S.; Meyrose, A.-K.; Manz, K.; Baumgarten, F.; et al. The relationship of self-reported and device-based measures of physical activity and health-related quality of life in adolescents. Health Qual. Life Outcomes 2021, 19, 67. [CrossRef] [PubMed]

29. Hagger, M.S.; Chatzisarantis, N.L.D.; Hein, V.; Pihu, M.; Soós, I.; Karsai, I. The perceived autonomy support scale for exercise settings (PASSES): Development, validity, and cross-cultural invariance in young people. Psychol. Sport Exerc. 2007, 8, 632-653. [CrossRef]

30. Goudas, M.; Biddle, S.; Fox, K. Perceived locus of causality, goal orientations, and perceived competence in school physical education classes. Br. J. Educ. Psychol. 1994, 64, 453-463. [CrossRef] [PubMed]

31. Kalajas-Tilga, H.; Koka, A.; Hein, V.; Tilga, H.; Raudsepp, L. Motivational processes in physical education and objectively measured physical activity among adolescents. J. Sport Health Sci. 2020, 9, 462-471. [CrossRef] [PubMed]

32. Koka, A.; Tilga, H.; Kalajas-Tilga, H.; Hein, V.; Raudsepp, L. Perceived Controlling Behaviors of Physical Education Teachers and Objectively Measured Leisure-Time Physical Activity in Adolescents. Int. J. Environ. Res. Public Health 2019, 16, 2709. [CrossRef] [PubMed]

33. Ryan, R.M.; Connell, J.P. Perceived locus of causality and internalization: Examining reasons for acting in two domains. J. Personal. Soc. Psychol. 1989, 57, 749-761. [CrossRef]

34. Ajzen, I. Constructing a TPB Questionnaire: Conceptual and Methodological Considerations. 2003. Available online: http: //people.umass.edu/aizen/pdf/tpb.measurement.pdf (accessed on 6 September 2018).

35. Pihu, M.; Hein, V.; Koka, A.; Hagger, M.S. How students' perceptions of teachers' autonomy-supportive behaviours affect physical activity behaviour: An application of the trans-contextual model. Eur. J. Sport Sci. 2008, 8, 193-204. [CrossRef] 
36. Koka, A.; Tilga, H.; Kalajas-Tilga, H.; Hein, V.; Raudsepp, L. Detrimental Effect of Perceived Controlling Behavior from Physical Education Teachers on Students' Leisure-Time Physical Activity Intentions and Behavior: An Application of the Trans-Contextual Model. Int. J. Environ. Res. Public Health 2020, 17, 5939. [CrossRef] [PubMed]

37. Godin, G.; Shephard, R.J. A simple method to assess exercise behavior in the community. Can. J. Appl. Sport Sci. 1985, 10, 141-146. [PubMed]

38. Hein, V.; Koka, A.; Kalajas-Tilga, H.; Tilga, H.; Raudsepp, L. The effect of grit on leisure time physical activity. An Application of Theory of Planned Behaviour. Balt. J. Health Phys. Act. 2020, 12, 78-85. [CrossRef]

39. Hein, V.; Koka, A.; Tilga, H.; Kalajas-Tilga, H.; Raudsepp, L. The Roles of Grit and Motivation in Predicting Children's Leisure-time Physical Activity: One-year Effects. Percept. Mot. Skills 2021. [CrossRef] [PubMed]

40. Tilga, H.; Kalajas-Tilga, H.; Hein, V.; Raudsepp, L.; Koka, A. How does perceived autonomy-supportive and controlling behaviour in physical education relate to adolescents' leisure-time physical activity participation? Kinesiology 2020, 52, 265-272. [CrossRef]

41. Viira, R.; Koka, A. Health-related quality of life of Estonian adolescents: Reliability and validity of the PedsQL ${ }^{\mathrm{TM}} 4.0 \mathrm{Generic}$ Core Scales in Estonia. Acta Paediatr. 2011, 100, 1043-1047. [CrossRef]

42. Varni, J.W.; Seid, M.; Kurtin, P.S. PedsQL 4.0: Reliability and validity of the Pediatric Quality of Life Inventory version 4.0 generic core scales in healthy and patient populations. Med. Care 2001, 39, 800-812. [CrossRef]

43. Tilga, H.; Hein, V.; Koka, A.; Hagger, M.S. How Physical Education Teachers' Interpersonal Behaviour is Related to Students' Health-Related Quality of Life. Scand. J. Educ. Res. 2020, 64, 661-676. [CrossRef]

44. Hu, L.; Bentler, P.M. Cutoff criteria for fit indexes in covariance structure analysis: Conventional criteria versus new alternatives. Struct. Equ. Model. Multidiscip. J. 1999, 6, 1-55. [CrossRef]

45. Byrne, B.M. Structural Equation Modeling with AMOS: Basic Concepts, Applications, and Programming, 2nd ed.; Routledge/Taylor \& Francis Group: London, UK, 2010.

46. Pihu, M.; Hein, V. Autonomy support from physical education teachers, peers and parents among school students: Transcontextual motivation model. Acta Kinesiol. Univ. Tartu. 2007, 12, 116-128.

47. Bronikowski, M.; Bronikowska, M.; Laudańska-Krzemińska, I.; Kantanista, A.; Morina, B.; Vehapi, S. PE Teacher and Classmate Support in Level of Physical Activity: The Role of Sex and BMI Status in Adolescents from Kosovo. BioMed Res. Int. 2015, 2015, 290349. [CrossRef]

48. Farooq, A.; Martin, A.; Janssen, X.; Wilson, M.G.; Gibson, A.-M.; Hughes, A.; Reilly, J.J. Longitudinal changes in moderate-tovigorous-intensity physical activity in children and adolescents: A systematic review and meta-analysis. Obes. Rev. 2020, 21, e12953. [CrossRef]

49. Cheon, S.H.; Reeve, J.; Ntoumanis, N. A needs-supportive intervention to help PE teachers enhance students' prosocial behavior and diminish antisocial behavior. Psychol. Sport Exerc. 2018, 35, 74-88. [CrossRef]

50. Sevil-Serrano, J.; Aibar, A.; Abós, Á.; Generelo, E.; García-González, L. Improving motivation for physical activity and physical education through a school-based intervention. J. Exp. Educ. 2020, 88, 351-357. [CrossRef]

51. Tilga, H.; Hein, V.; Koka, A. Effects of a Web-Based Intervention for PE Teachers on Students' Perceptions of Teacher Behaviors, Psychological Needs, and Intrinsic Motivation. Percept. Mot. Skills 2019, 126, 559-580. [CrossRef] [PubMed]

52. Tilga, H.; Kalajas-Tilga, H.; Hein, V.; Raudsepp, L.; Koka, A. 15-Month Follow-Up Data on the Web-Based Autonomy-Supportive Intervention Program for PE Teachers. Percept. Mot. Skills 2020, 127, 5-7. [CrossRef] [PubMed]

53. Cheon, S.H.; Reeve, J.; Yu, T.H.; Jang, H.R. The teacher benefits from giving autonomy support during physical education instruction. J. Sport Exerc. Psychol. 2014, 36, 331-346. [CrossRef] [PubMed]

54. Tilga, H.; Kalajas-Tilga, H.; Hein, V.; Raudsepp, L.; Koka, A. Effects of a Web-Based Autonomy-Supportive Intervention on Physical Education Teacher Outcomes. Educ. Sci. 2021, 11, 316. [CrossRef]

55. Burgueño, R.; Abós, Á.; García-González, L.; Tilga, H.; Sevil-Serrano, J. Evaluating the Psychometric Properties of a Scale to Measure Perceived External and Internal Faces of Controlling Teaching among Students in Physical Education. Int. J. Environ. Res. Public Health 2021, 18, 298. [CrossRef]

56. Tilga, H.; Hein, V.; Koka, A.; Hamilton, K.; Hagger, M.S. The role of teachers' controlling behaviour in physical education on adolescents' health-related quality of life: Test of a conditional process model. Educ. Psychol. 2019, 39, 862-880. [CrossRef]

57. Tilga, H.; Hein, V.; Koka, A. Measuring the perception of the teachers' autonomy-supportive behavior in physical education: Development and initial validation of a multi-dimensional instrument. Meas. Phys. Educ. Exerc. Sci. 2017, 21, 244-255. [CrossRef]

58. Koka, A.; Tilga, H.; Hein, V.; Kalajas-Tilga, H.; Raudsepp, L. A multidimensional approach to perceived teachers' autonomy support and its relationship with intrinsic motivation of students in physical education. Int. J. Sport Psychol. 2020, in press.

59. Montero-Carretero, C.; Barbado, D.; Cervelló, E. Predicting Bullying through Motivation and Teaching Styles in Physical Education. Int. J. Environ. Res. Public Health 2020, 17, 87. [CrossRef] [PubMed]

60. Zimmermann, J.; Tilga, H.; Bachner, J.; Demetriou, Y. The German Multi-Dimensional Perceived Autonomy Support Scale for Physical Education: Adaption and Validation in a Sample of Lower Track Secondary School Students. Int. J. Environ. Res. Public Health 2020, 17, 7353. [CrossRef] [PubMed]

61. Zimmermann, J.; Tilga, H.; Bachner, J.; Demetriou, Y. The Effect of Teacher Autonomy Support on Leisure-Time Physical Activity via Cognitive Appraisals and Achievement Emotions: A Mediation Analysis Based on the Control-Value Theory. Int. J. Environ. Res. Public Health 2021, 18, 3987. [CrossRef] [PubMed] 